\title{
Multidrug-Resistant Urinary Tract Isolates of Escherichia coli from Ribeirão Preto, São Paulo, Brazil
}

\author{
Edilene Santo ${ }^{1}$, Miriam Mendonça Salvador ${ }^{2}$ and José Moacir Marin ${ }^{2}$ \\ ${ }^{I}$ Department of Microbiology, Julio de Mesquita Filho University - UNESP - Jaboticabal, São Paulo; ${ }^{2}$ Departament of Morphology, \\ Stomatology and Phisiology - FORP, São Paulo University - Campus Ribeirão Preto, Brazil
}

\begin{abstract}
Multiple resistances to antimicrobial drugs arising in Escherichia coli isolates may complicate therapeutic management of urinary tract infection (UTI) by this organism. In order to assess the multidrug resistance (MDR) among urinary $E$. coli isolates, we have tested 11 antimicrobial drugs against 67 isolates from outpatients attended in a tertiary-care teaching hospital and of 78 isolates from a municipal health unit, respectively in Ribeirão Preto, State of São Paulo, Brazil. Seventy-six percent and $22 \%$ of the isolates from the tertiary-care hospital and the municipal unit, respectively, were resistant to three or more different classes of agents, and were considered to present MDR. Among the isolates from the hospital patients, $73.0 \%, 65.0 \%, 58.0 \%, 58.0 \%$ and 31.0\% were resistant to tetracycline, ampicillin, cephalothin, trimethoprim-sulfamethoxazole (TMP/SMX) and norfloxacin, respectively; resistance from the municipal unit patients were $31.0 \%, 37.0 \%, 8.0 \%, 29.0 \%$ and $12.0 \%$ respectively, to the same drugs. The predominant phenotype among the MDR isolates presented is ampicillin, TMP/SMX and tetracycline resistance. The high prevalence of drug resistance among UTI patients calls for continuous surveillance to assure effective control of this infection.
\end{abstract}

Key-Words: Urinary tract infections, Escherichia coli, antimicrobial susceptibility, multidrug-resistance.

Urinary tract infections (UTIs) having as etiologic agent Escherichia coli are common infections with an estimated annual global incidence of at least 250 million cases, being costly to both patients and health care funding system [1].

Non-complicated infections, particularly in women, account for the highest number of UTIs. Women diagnosed for acute uncomplicated cystitis are usually treated as outpatients: the microbiologic characteristics of this infection are highly predictable even in otherwise healthy subjects. Physicians have therefore been advised that empirical antimicrobial treatment not requiring culture is appropriate in such cases [2]. Therefore, the empirical therapy has been so widely used that a few UTIs were routinely cultured. However studies clearly demonstrated an increasing antibiotic resistance in E. coli causing both community- and nosocomially acquired UTIs $[3,4]$.

Updated knowledge of causal bacteria and their susceptibility patterns are important for proper selection and use of antibiotics as well as for an appropriate prescribing policy. The aim of the present study was to define current occurrence and phenotypes of multidrug-resistant (MDR) $E$. coli among UTI isolates from respectively a municipal health unit and an outpatient facility from a tertiary-care teaching hospital in Ribeirão Preto.

\section{Material and Methods}

Bacterial Isolates

A total of 67 strains of E. coli were isolated from eight subjects aged between 0 and 15 years (eight women [w] ), 11 aged between 16 and 39 years ( $10 \mathrm{w}$ and one man $[\mathrm{m}]$ ) and 48

Received on 15 June 2007; revised 30 September 2007.

Address for correspondence: Dr. José Marin. Phone: 01636024101 , Fax: 016 36330999. E-mail address: jmmarin@forp.usp.br.

The Brazilian Journal of Infectious Diseases 2007;11(6):575-578. (C) 2007 by The Brazilian Journal of Infectious Diseases and Contexto Publishing. All rights reserved. aged $>40$ years ( $22 \mathrm{w}$ and $26 \mathrm{~m}$ ) from the outpatient facility of the Clinical Hospital of the School of Medicine of Ribeirão Preto (HCFMRP), a university tertiary-care hospital, "tertiary care", and 78 strains were isolated from nine subjects aged between 0 and 15 years $(8 \mathrm{w}$ and $1 \mathrm{~m}), 36$ aged between 16 and 39 years ( $35 \mathrm{w}$ and $1 \mathrm{~m}$ ) and 33 aged $>40$ years $(28 \mathrm{w}$ and $5 \mathrm{~m}$ ) from a municipal basic health unit, "primary care". Isolates were collected between July 2000 and July 2003. UTI diagnoses were established by the medical staff, on the basis of clinical symptoms and laboratory investigation. The isolation and identification of $E$. coli strains were performed by minimal standard bacteriological tests, using conventional biochemical markers $[5,6]$; one isolate per patient was evaluated.

\section{Susceptibility Testing}

Antimicrobial susceptibility was determined by the Kirby-Bauer disk diffusion method following the definition of the National Committee of Clinical Laboratory Standards (NCCLS) for agar diffusion tests [7] using antibioticcontaining disks from CEFAR Diagnostica Ltda (São Paulo, Brazil), as well as the manufacturer instructions about the clear zones of growth inhibition around the disks. The antimicrobial drugs used were: ampicillin $(10 \mu \mathrm{g})$, cephalothin $(30 \mu \mathrm{g})$, cefoxitin $(30 \mu \mathrm{g})$, cefuroxime $(30 \mu \mathrm{g})$, ceftriaxone $(30 \mu \mathrm{g})$, gentamicin $(10 \mu \mathrm{g})$, tobramycin $(10 \mu \mathrm{g})$, tetracycline $(30 \mu \mathrm{g})$, norfloxacin $(10 \mu \mathrm{g})$, nitrofurantoin (300 $\mu \mathrm{g}$ ), cotrimoxazole (sulfamethoxazole $23.75 \mu \mathrm{g}+$ trimethoprim $1.75 \mu \mathrm{g}$ ). Quality control was performed using E. coli ATCC 25922. An isolate was considered multidrugresistant (MDR) if it was resistant to at least three of the antimicrobial agents tested.

\section{Results}

The resistance of $E$. coli isolates to antimicrobial agents is shown in Figure 1. The overall resistances to tetracycline, ampicillin, cephalothin and cotrimoxazole (trimethoprim/ 
Figure 1. Antimicrobial resistance of Escherichia coli isolates from patients attended in an outpatient facility from a tertiarycare teaching hospital and a municipal health care center in Ribeirão Preto, SP.

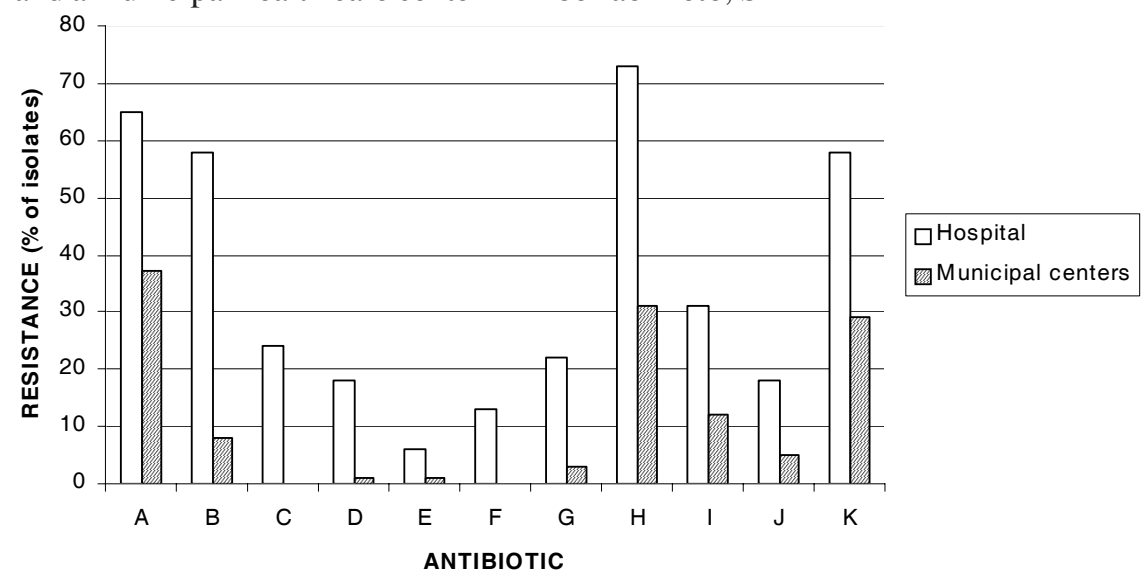

$\mathrm{A}=$ Ampicillin; $\mathrm{B}=$ Cephalothin; $\mathrm{C}=$ Cefoxitin; $\mathrm{D}=$ Cefuroxime; $\mathrm{E}=$ Ceftriaxone; $\mathrm{F}=$ Gentamicin $\mathrm{G}=$ Tobramycin; H=Tetracycline; I=Norfloxacin; $\mathrm{J}=$ Nitrofurantoin; K=Cotrimoxazole (Trimethoprim/sulfamethoxazole).

sulfamethoxazole-TMP/SMX) were higher than $50 \%$ for the isolates from hospital patients. Taken all together the results showed that the rates of resistance found among the E. coli isolates from the hospital patients reached twice as high resistances as the isolates from the municipal health unit patients. Among aminoglycosides, gentamicin was the most active agent in both situation with $13 \%$ and $0 \%$ of resistance among the hospital and municipal center isolates, respectively. A high resistance to norfloxacin was observed, $31.0 \%$ in the isolates from hospital patients and $12.0 \%$ in the municipal unit isolates.
Among the strains tested against all 11 antimicrobial agents, the percentage of isolates showing MDR was high in the hospital patients (76.0\%) and in the municipal unit samples $(22.0 \%)$ (Table 1). The stratification of the results showed that most of the isolates from hospital patients present multidrug resistance to three or more antimicrobial agents while a lot of isolates from municipal center patients present susceptibility to all the antimicrobial drugs or resistance to one drug (Table 1). The most common MDR phenotype showed was overall resistance to ampicillin, TMP/SMX and tetracycline (Table 2) and it was more prevalent among municipal unit patients.

Table 1. Resistance to one or more antimicrobial agents among the Escherichia coli urinary tract isolates studied

$\mathrm{N}^{0}$ of agents to which isolates were resistant

\begin{tabular}{ccc}
\cline { 2 - 3 } & Hospital & Municipal center \\
\hline 0 & $13.0(9 / 67)$ & $42.0(33 / 78)$ \\
1 & $6.0(4 / 67)$ & $18.0(14 / 78)$ \\
2 & $5.0(3 / 67)$ & $18.0(14 / 78)$ \\
$3-4$ & $40.0(27 / 67)$ & $10.0(8 / 78)$ \\
$5-7$ & $28.0(19 / 67)$ & $8.0(6 / 78)$ \\
$8-11$ & $8.0(5 / 67)$ & $4.0(3 / 78)$ \\
\hline
\end{tabular}

Table 2. The most common antimicrobial resistance phenotypes showing multidrug-resistance among Escherichia coli urinary tract isolated from patients attended, respectively, in an outpatient facility from a hospital and in a municipal unit.

\begin{tabular}{lcc}
\hline Antimicrobial resistance phenotype & Hospital (No of isolates) & Municipal unit (No of isolates) \\
\hline AMP,CFL,TMP/SMX,TET & 7 & - \\
CFL, TET,TOB & 7 & - \\
NIT,NOR,AMP,CFL,TMP/SMX,TET,CMX & 5 & - \\
AMP,CFL,TMP/SMX & 3 & - \\
NOR,AMP,CFL,TMP/SMX,TET & 3 & 6 \\
AMP,TET,TMP/SMX & 2 & - \\
\hline
\end{tabular}

* - not found. AMP-ampicillin, CFL-cephalothin, TMP/SMX-trimethoprim/sulfamethoxazole, TET-tetracycline, TOBtobramycin, NIT-nitrofurantoin, NOR-norfloxacin, CMX-cefuroxime. 


\section{Discussion}

This study provides data about the problem of resistance in $E$. coli isolates obtained from patients attended in an outpatient facility from a tertiary-care hospital and in a municipal health unit. Results have demonstrated that in general the $E$. coli isolates have high rates of resistance to the commonly used antibiotics. The rates of resistance reported in this study were much higher than those published in developed countries $[8,9]$ but are similar to those reported in other developing countries [10-12].

The rates we report in the present study for patients from the hospital agree with those reported by Gales et al. $[3,13]$ in antimicrobial surveillance studies in Latin American hospitals including some from Brazil, but are higher than those reported for French [14] or British [15] hospitalized patients.

Many factors may have contributed to such high rates of resistance including misuse of antibiotics by health care professionals or non-skilled practitioners, misuse of antibiotics by the general public (antibiotics can be purchased in Brazil without a prescription), and inadequate surveillance due to lack of information arising from routine antimicrobial susceptibility testing, like reports from other developing countries [16] The resistance rates to isolates from municipal units reported in the present study were equal to [17], higher [8] or lower [10] than others, but, in all of them, the reported rate of fluoroquinolone resistance was lower than that observed in the present study. Furthermore, in the USA a gradual decrease in the susceptibility of $E$. coli to fluoroquinolones has been reported $[18,19]$; increased resistance to fluoroquinolones was also demonstrated in Portugal and Spain [20]. The data reported in this study agree with the study described by Poletto and Reis [21] to E. coli isolates from outpatients (primary care) from Goiânia, especially the resistance level to fluoroquinolones (norfloxacin) and the sensitivity to gentamicin.

A significant increase in resistance of uropathogenic strains to TMP-SMX, ampicillin and cephalothin has been found worldwide [9,22], what agree with the results reported in the present study, therefore these agents should not be recommended for first line empirical treatment of UTI [23]. Older agents like gentamicin and nitrofurantoin, that still show high efficacy against UTI pathogens in Brazil [3,21], should be considered as options for treatment. Nitrofurantoin as an option for empirical therapy has been considered by many authors $[3,8]$, since its multiple mechanisms of action seem to have enabled it to retain potent activity against $E$. coli despite nearly 50 years of use [24].

In the present study (Table 1), the percentage of isolates demonstrating a MDR phenotype was extremely high, especially in isolates from hospital as compared to rates reported in the USA [9]. The most frequently observed multidrug resistance phenotypes agreed with those already reported, in special for ampicillin, cephalothin and TMP-SMX [8,9].

In conclusion, E. coli involved in UTIs isolated from patients attended in an outpatient facility from a tertiary-care hospital or in a municipal health unit showed resistance for many antimicrobial agents. Also, the high number of multidrugresistant isolates gives rise to concern. Regular monitoring of antimicrobial drugs resistance seems necessary to improve our guidelines for empirical antibiotic therapy.

\section{Acnowledgment}

The authors thank Tania Marques for technical assistance. This work is part of a thesis submitted by Edilene Santo to UNESP in partial fulfillment of the requirements for the Master's degree.

\section{References}

1. Ronald A.R., Nicolle, L.E., Stamm E., et al. Urinary tract infection in adults: research priorities and strategies. Int. J. Antimicrob. Agents 2001; 17:343-8.

2. Hooton T.M., Stamm W.E. Diagnosis and treatment of uncomplicated urinary tract infection. Infect Dis Clin North Am 1997; 11:551-81.

3. Gales A.C., Sader H.S., Jones R.N., et al. Urinary tract infection trends in Latin American hospitals: report from the SENTRY antimicrobial surveillance program (1997-2000). Diag Microb Infect Dis 2000;44:289-99.

4. Gupta K., Hooton T.M., Wobbe C.L., et al. The prevalence of antimicrobial resistance among uropathogens causing acute uncomplicated cystitis in young women. Int J Antimicrob Agents 1999; $11: 305-8$

5. Bergey's Manual of Systematic Bacteriology, Baltimore: Williams \& Wilkins, 1994.

6. Farmer J.J. Enterobacteriaceae: Introduction and identification. In: Manual of clinical microbiology $7^{\text {Th }}$ ed (Murray, P.R., Baron, E.J., Phaler, M.A., Tenover, F.C., Yolken, R.H. eds), ASM Press, Washington, D.C, 1999.

7. National Committee for Clinical Laboratory Standards. Performance Standards for Antimicrobial Susceptibility Testing. Ninth Informational Supplement M100-S9, 1999.

8. Karlowsky, J.A., Kely, L.J., Thonsberry, C., et al. Trends in antimicrobial resistance among urinary tract infection isolates of Escherichia coli from female outpatients in the United States. Antimicrob. Agents Chemother 2002; 46:2540-45.

9. Sahm D.F., Thonsberry C., Mayfield D.C., et al. Multidrug-resistant urinary tract isolates of Escherichia coli: Prevalence and patient demographics in the United States in 2000. Antimicrob. Agents Chemother 2001;45:1402-6.

10. Lee S.J., Lee S.D., Cho I.R., et al. Antimicrobial susceptibility of uropathogens causing acute uncomplicated cystitis in female outpatients in South Korea: a multicentre study in 2002. Int J Antimicrob Agents 2004;24S:S61-4.

11. Matute A.J., Hak E., Sccurink C.A.M., et al. Resistance of uropathogens in symptomatic urinary tract infections in Leon, Nicaragua. Int J Infect Dis 2004;23:506-9.

12. Pieboji J.G., Koula-Shiro S., Ngassam P.P., et al. Antimicrobial resistance of Gram-negative bacilli isolates from inpatients and outpatients at Yaounde Central Hospital, Cameron. Int J Infect Dis 2004; 8 : 147-54.

13. Gales A.C., Jones R.N., Gordon K.A., et al. Activity and spectrum of 22 antimicrobial agents tested against urinary tract infection pathogens in hospitalized patients in Latin America: report from the second year of the SENTRY Antimicrobial Surveillance Program (1998). J Antimicrob Chemother 2000;45:295-303.

14. Sotto A., Boever C.M., Fabro-Peray P., et al. Risk factors for antibiotic-resistant Escherichia coli isolated from hospitalized patients with urinary tract infections: a prospective study. J Clin Microbiol 2001;39:438-44. 
15. Farrel D.J., Morrissey I., DE Rubeis D., et al. A UK multicentre study of the antimicrobial susceptibility of bacterial pathogens causing urinary tract infection. J Infection 2003;46:94-100.

16. Okeke I.N., Lamikanra A., Edelman R. Socio-economic and behavioral factors leading to acquired bacterial resistance to antibiotics in developing countries. Emerg Infect Dis 1999;5:18-27.

17. Barisic Z., Babic-Erceg A., Borzic E., et al. Urinary tract infections in South Croatia: aetiology and antimicrobial resistance. Int J Antimicrob Agents 2003;22:S61-S4.

18. Jones R.N., Kugler K.C., Pfaller M.A., et al. Characteristics of pathogens causing urinary tract infections in hospitals in North America: results from the SENTRY antimicrobial surveillance program, 1997. Diagn Microbiol Infect Dis 1999;35:55-63.

19. Mathai D., Jones R.N., Pfaller M.A., et al. Epidemiology and frequency of resistance among pathogens causing urinary tract infections in 1,510 hospitalized patients: a report from the SENTRY Antimicrobial Surveillance Program (North America). Diagn Microbiol Infect Dis 2001;40:129-36.
20. Kahlmeter G. The ECO-SENS project: a prospective, multinational multicentre epidemiological survey of the prevalence and antimicrobial susceptibility of urinary tract pathogen-interim report. J Antimicrob Chemother 2000;46(Suppl):15-22.

21. Poletto K.Q., Reis C. Susceptibilidade antimicrobiana de uropatógenos em pacientes ambulatoriais na cidade de Goiânia, GO. Rev Soc Bras Med Tropical 2005;38:416-20.

22. Hooton T.M. Fluoroquinolones and resistance in the treatment of uncomplicated urinary tract infection. Int J Antimicrob Agents 2003;22:S65-S72.

23. Warren J.W., Abrutyn E., Hebel J.R., et al. Guidelines for antimicrobial treatment of uncomplicated acute bacterial cystitis and acute pyelonephritis in women. Infectious Diseases Society of America (IDSA). Clin Infect Dis 1999;29:745-58.

24. McOsker C.C., Fitzpatrick P.M. Nitrofurantoin mechanisms of action and implications for resistance development in common uropathogens. J Antimicrob Chemother 1994;33(Supl):23-30. 